\title{
Secas e Impactos na Agropecuária no Município de Campina Grande - PB
}

\author{
Julian Gomes Pedrosa Duarte ${ }^{1}$, André Aires de Farias ${ }^{2}$ (iD, \\ Francisco de Assis Salviano de Sousa ${ }^{3}$, José Thyago Aires Souza ${ }^{4}$, \\ Marília Maria Quirino Ramos ${ }^{5}$ \\ ${ }^{1}$ Universidade Estadual da Paraiba, Campina Grande, PB, Brasil. \\ ${ }^{2}$ Escola Agrotécnica de Sumé, Sumé, PB, Brasil. \\ ${ }^{3}$ Universidade Federal de Campina Grande, Campina Grande, PB, Brasil. \\ ${ }^{4}$ Universidade Federal da Paraíba, Areia, PB, Brasil. \\ ${ }^{5}$ Universidade Estadual da Paraiba, Campina Grande, PB, Brasil.
}

Recebido em 23 de Junho de 2017 - Aceito em 9 de Agosto de 2017.

\begin{abstract}
Resumo
Objetivou-se neste estudo identificar e analisar as secas e seus impactos na agropecuária no município de Campina Grande - PB. Foram utilizados dados de totais mensais precipitados para o período de 1994-2015 do município de Campina Grande para analisar duração, déficit hídrico e intensidade das secas nesse período. Para análise dos impactos foram utilizados dados de agricultura, pecuária e produtos agropecuários obtidos no Instituto Brasileiro de Geografia e Estatística. As secas mais graves no município, aquelas com as maiores durações, déficits hídricos e intensidades, ocorreram nos períodos de 1997-1999, 2012-2015 e 2001-2003. As culturas permanentes tiveram maior impacto na quantidade produzida e rendimento médio. Já as temporárias tiveram redução de área plantada, área colhida, quantidade produzida, rendimento médio e valor da produção. Os maiores impactos ocorreram para banana, coco, mamão, feijão e milho durante 2012 e 2013. Ocorreu redução do efetivo de animais durante a seca, principalmente em 2012 e 2013 . A maior redução foi apresentada pelos rebanhos bovino, caprino e ovino. Com relação aos produtos agropecuários, só houve redução da quantidade e do valor da produção de leite durante 2012 e 2014.
\end{abstract}

Palavras-chave: fenômeno natural, gravidade das secas, produção agropecuária.

\section{Droughts and Impacts on Agriculture in the Municipality of Campina Grande - PB}

\begin{abstract}
This study aimed to identify and analyze the droughts and its impacts on agriculture in the municipality of Campina Grande - PB. Were used of monthly total data precipitates for the period 1994-2015 of Campina Grande municipality to analyze duration, water deficit and intensity of droughts in this period. To analyze the impacts were used data of agriculture, livestock and agricultural products obtained from the Brazilian Institute of Geography and Statistics. The most severe droughts in the municipality, those with longer durations, water deficits and intensities occurred in the periods of 1997-1999, 2012-2015 and 2001-2003. The permanent crops had greater impact on the quantity produced and average income. Already had temporary acreage reduction, harvested area, amount produced, average yield and production value. The greatest impacts occurred banana, coconut, papaya, bean and corn during 2012 and 2013. There was a reduction of the effective animals during drought, especially in 2012 and 2013. The largest reduction was presented by bovine cattle, goats and sheep. With regard to agricultural products, only decreased the quantity and value of milk production during 2012 and 2014.
\end{abstract}

Keywords: natural phenomenon, severity of droughts, agricultural production.

Autor de correspondência: André Aires de Farias, andreaires61@hotmail.com. 


\section{Introdução}

Seca é um fenômeno natural que ocorre quando a precipitação anual é inferior aos índices registrados em anos de precipitação considerada normal. Dependendo da duração, déficit e intensidade, as secas podem ser classificadas em quatro categorias: fraca, moderada, severa e extrema. Embora a causa primária das secas resida na irregularidade das precipitações pluviais, existe uma sequência de causas e efeitos que acontecem em função da intensidade dos eventos e dos tipos de secas, que podem ser: meteorológica, agrícola, hidrológica e socioeconômica (Farias, 2016).

As secas são geralmente classificadas em quatro tipos (Wilhite e Glantz, 1985). Estes incluem:

- Seca meteorológica, que é definida como um déficit de precipitação pluvial sobre uma região, durante um período de tempo. Dados de precipitação têm sido comumente utilizados para análise de seca meteorológica (Hayes et al., 1999).

- Seca agrícola, refere-se à baixa disponibilidade de umidade no solo, a qual torna o suprimento de água às culturas insuficiente para repor as perdas por evapotranspiração. Diversas pesquisas com base em uma combinação de precipitação, temperatura e umidade do solo foram realizadas para estudar secas agrícolas, entre elas: Nandintsetseg e Shinoda (2013).

- Seca hidrológica, que está relacionada com uma deficiência no volume de água disponível, incluindo lençol freático, reservatórios e rios. Dados de vazão têm sido amplamente utilizados para análise de seca hidrológica (Clausen e Pearson, 1995).

- Seca socioeconômica, que está associada à insuficiência dos sistemas de recursos hídricos para atender às demandas de água, associando, assim, secas com a oferta e a procura de um bem econômico. Ocorre quando a demanda por um bem é superior à oferta.

As estimativas do número de pessoas no Nordeste Brasileiro (NEB) atingidas pelas grandes secas recentes mostram a amplitude da calamidade por elas provocadas: 16 milhões entre 1979-1984, 12 milhões em 1993 e 10 milhões em 1998. A quantidade de trabalhadores alistados nestas secas, embora impressionantes, se encaradas como programas de socorro às vítimas de uma calamidade, mostram, por outro lado, que o número de flagelados atendidos é pequeno em relação ao total de pessoas atingidas. Para evitar que a população se deslocasse em massa, foi necessário a criação de frentes de trabalho. Foram estes os totais de trabalhadores alistados nas últimas grandes secas: 500 mil em 1970, 2,7 milhões entre 1979-1984, 2 milhões em 1993 (Projeto Áridas, 1998) e 1,2 milhão em 1998 (Brasil. Sudene, 1998).

No NEB, analisando os efeitos da seca ocorrida no período de 1979-1984, Khan e Campos (1992) estimaram que as perdas totais do período chegaram aos impressio- nantes números de 1,6 milhão de toneladas de algodão (Gossypium hirsutum L.), 1 milhão de tonelada de mandioca (Manihot esculenta Crantz), 3 milhões de toneladas de milho (Zea mays), 952 mil toneladas de feijão (Phaseolus vulgaris), além de perdas de diversos outros produtos.

Outra seca de grandes proporções aconteceu nos anos de 1998-2000, sendo causada pelo El Niño, este foi considerado o mais forte do século. Essa seca provocou, no NEB, grandes impactos sociais, econômicos e ambientais. Entre estes, estão inclusos a perda considerável dos rebanhos, a quebra generalizada da safra agrícola, além dos transtornos no abastecimento de água das zonas urbanas e rurais. Ainda estão vivas na mente da população, cenas que a imprensa nacional divulgava: agricultores assando palma forrageira (Variedade Gigante) (Opuntia fícus indica) para alimentar a família; bovinos (Bos indicus), caprinos (Capra hircus) e ovinos (Ovis aries) morrendo diariamente pela falta de alimentos e água; crianças caçando aves e répteis para se alimentarem; mulheres e crianças caminhando quilômetros para transportar, na cabeça, latas de água de péssima qualidade. A estas cenas comoventes e humilhantes, somavamse outras, reveladoras do desespero de grupos de pessoas famintas saqueando feiras livres e caminhões (Farias, 2016).

Até o presente momento, a literatura sobre os impactos da seca de 2012-2017 no NEB ainda é muito escassa, a maioria das informações estão em jornais na internet e são referentes às conjunturas locais, não existindo estudos que agreguem uma quantidade de informações regionais ou mesmo nacional. O que existe de concreto é que a região foi castigada por severos impactos na agropecuária. A falta de chuva que afeta a vida de milhões de brasileiros no NEB têm deixado marcas profundas na atividade econômica. $\mathrm{E}$ não é só na agricultura e na pecuária, a seca causou indisponibilidade de água em aproximadamente 95\% dos reservatórios, o colapso no abastecimento vem provocando uma crise sem precedentes nos municípios (Farias, 2016).

Em pesquisa realizada no município de Boqueirão PB, Farias et al. (2017) identificaram que as secas mais graves no município ocorreram nos anos de 1980-1982, 1998-2000 e 2012-2013. Destas, a mais impactante foi a de 1998-2000. Além de muitos outros impactos, essa seca reduziu drasticamente a produção agropecuária e o abastecimento de água da região. Os impactos mais intensos durante a seca 2012-2014 ocorreram em 2012 e 2013. As culturas agrícolas temporárias foram mais impactadas do que as permanentes. Isso ocorreu porque a maioria das permanentes eram irrigadas, diferente das temporárias. A maior redução de animais também ocorreu durante 2012 e 2013, com uma relação direta entre precipitação e efetivo dos rebanhos. Não houve redução do valor da produção em função das secas.

Data de 1583 o primeiro relato de uma seca no Nordeste do Brasil (NEB), feito pelo Padre Fernão Cardin, 
(Brasil, 1981), porém é consenso que o fenômeno seca é tão antigo quanto o surgimento do ser humano na Terra. Então, os seguintes questionamentos são levantados para o município de Campina Grande-PB: Em que anos ocorreram secas mais graves na série 1994-2015? Quais foram os impactos da seca de 2012-2014? Diante do que foi apresentado, objetivou-se identificar e analisar as secas e seus impactos na agropecuária no município de Campina Grande - PB.

\section{Material e Métodos}

A área de estudo compreende o município de Campina Grande-PB, localizado na Mesorregião do Agreste Paraibano e na Microrregião Campina Grande (Fig. 1).

Os dados pluviométricos foram obtidos através da Agência Executiva de Gestão das Águas do Estado da Paraíba (AESA). Foram utilizados dados de totais mensais precipitados para o período de 1994-2015 do município de
Campina Grande. Mesmo sendo seco, não foi possível analisar 2016, pois o ano ainda não havia terminado no momento da pesquisa. Através do Run method foram analisados: duração, déficit hídrico e intensidade das secas nesse período.

\section{Onde:}

- Duração L(s), definida como o número de intervalos consecutivos em que a variável permaneceu abaixo do limiar;

- Déficit hídrico D(s), definido como a soma dos desvios negativos, estendido para todo o período da seca;

- Intensidade ID(s), definida como a relação entre o déficit e a duração.

O Run method foi utilizado com o objetivo de identificar períodos de secas e avaliar suas propriedades estatísticas. De acordo com esse método, um período de seca coincide com um valor de precipitação, definida como uma série consecutiva de intervalos, onde a variável hidrológica

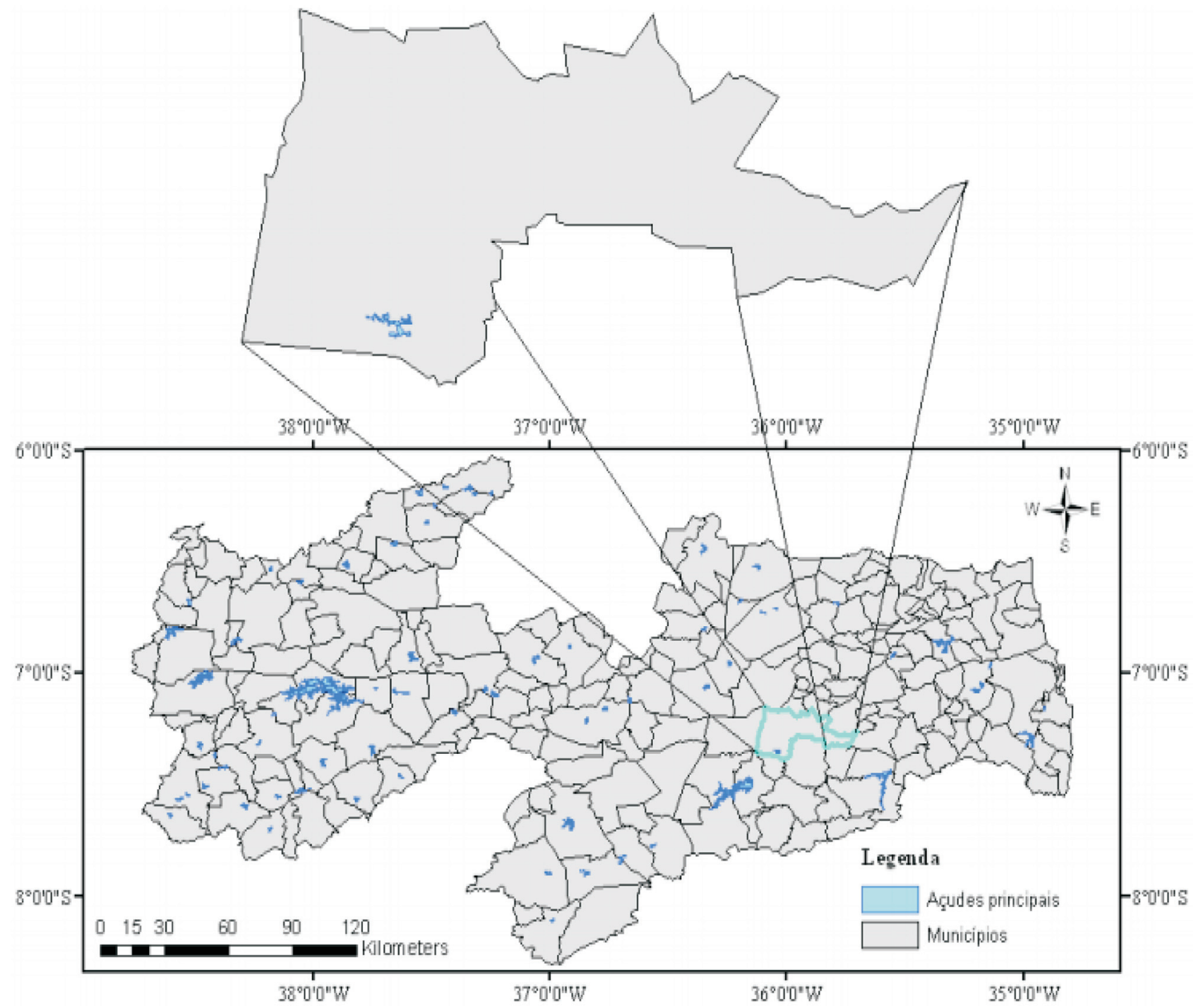

Figura 1 - Localização geográfica do município de Campina Grande - PB. Fonte: (Macedo et al., 2011). 
permanece abaixo de um valor médio (Yevjevich, 1967). A vantagem de usar o método consiste na possibilidade de identificar as características da seca, como duração, déficit hídrico, intensidade, período de retorno e tendência (Cancelliere et al., 1998).

Para análise dos impactos foram utilizados dados obtidos no Instituto Brasileiro de Geografia e Estatística (IBGE). Na agricultura foram analisados área plantada (ha), área colhida (ha), quantidade produzida (ton), rendimento médio $(\mathrm{kg} / \mathrm{ha})$ e valor da produção $(\mathrm{R} \$)$ de abacate, banana, coco, goiaba, laranja, mamão, manga, algodão herbáceo, fava, feijão, mandioca, milho e tomate dos anos de 2011, 2012, 2013 e 2014.

$\mathrm{Na}$ pecuária foi analisado o efetivo dos rebanhos de asininos, bovinos, caprinos, codornas, equinos, muares, ovinos e suínos dos anos de 2011, 2012, 2013 e 2014.

Com relação aos produtos agropecuários, foram utilizadas as variáveis: leite de vaca (quantidade), leite de vaca (valor da produção R\$), ovos de galinha (quantidade) e ovos de galinha (valor da produção R\$) dos anos de 2011, 2012, 2013 e 2014.

\section{Resultados e Discussão}

No município foram identificadas seis secas no período 1994-2015, que ocorreram em 1995, 1997-1999, 20012003, 2006-2007, 2010 e 2012-2015. Anos com chuvas acima da média atingiram o município em 1994, 2000, 2004, 2005, 2008, 2009 e 2011. Houve grande variabilidade temporal da precipitação, com anos chuvosos e secos alternando-se com frequência (Fig. 2).

As secas mais graves foram as de 1997-1999, 20122015 e 2001-2003. Estas tiveram durações de 3, 4 e 3 anos; déficit hídrico de 903, 608 e 322 mm; e intensidade de 301, 152 e 107,33 mm/ano, respectivamente, (Tabela 1).

Os impactos das duas primeiras secas foram mais intensos para os pequenos agricultores. Isso ocorreu em função da maioria dos pequenos proprietários não terem condições financeiras para armazenar água e alimento para animais e pessoas; as condições desfavoráveis para irrigação; pobreza, entre outros. Mesmo não estando no municí-

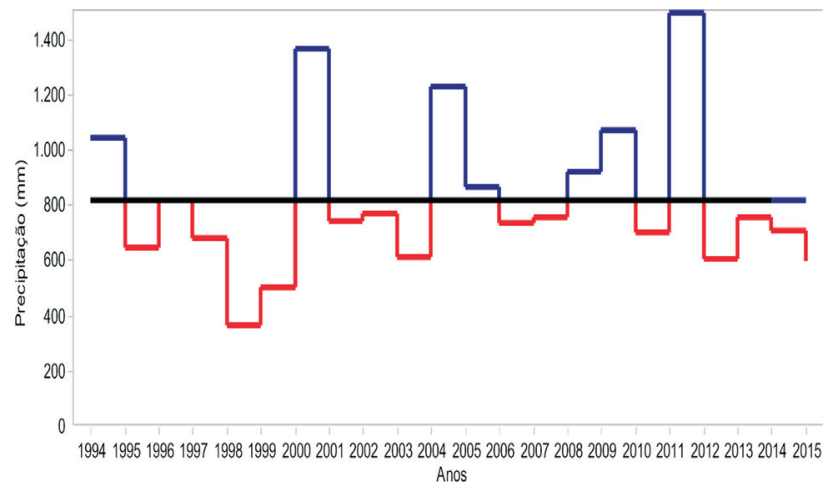

Figura 2 - Precipitação anual no período de 1994-2015 do município de Campina Grande - PB. Fonte: (AESA, 2016).
Tabela 1 - Duração, déficit hídrico e intensidade de secas no município de Campina Grande - PB.

\begin{tabular}{lccccc}
\hline Quant. & Início & Fim & $\begin{array}{c}\text { Duração } \\
\text { (anos) }\end{array}$ & $\begin{array}{c}\text { Déficit } \\
\text { hídrico } \\
\text { (mm) }\end{array}$ & $\begin{array}{c}\text { Intensidad } \\
\text { e } \\
\text { (mm/ano) }\end{array}$ \\
\hline 1 & 1997 & 1999 & 3 & 903,00 & 301,00 \\
2 & 2012 & 2015 & 4 & 608,00 & 152,00 \\
3 & 2001 & 2003 & 3 & 322,00 & 107,33 \\
4 & 2006 & 2007 & 2 & 143,00 & 71,50 \\
5 & 1995 & 1995 & 1 & 169,00 & 169,00 \\
6 & 2010 & 2010 & 1 & 117,00 & 117,00 \\
\hline
\end{tabular}

Fonte: (AESA, 2016).

pio, outro fator tornou a situação ainda mais difícil: a redução do volume de água do Açude Epitácio Pessoa.

Com a escassez de chuvas nos municípios a montante do açude Epitácio Pessoa durante 1997-1999, o manancial não foi reabastecido. Isso fez com que fosse adotado o racionamento de água nos anos de 1998, 1999 e 2001, começando quando o açude tinha um volume próximo de 100.000.000 de $\mathrm{m}^{3}$ de água. Este foi um período crítico, haja vista que suas águas abastecem diversos municípios, entre eles, Campina Grande.

A seca de 2012-2015 (2016) causou muitos impactos à população que dependia das águas do Epitácio Pessoa. Com precipitações abaixo da média nas bacias hidrográficas do Alto Paraíba e Taperoá durante esses anos, o volume foi sendo reduzido dia após dia. E mais uma vez o racionamento se fez presente, tendo início em dezembro de 2014, passando por 2015 e 2016. Atualmente (Junho de 2017) o problema ainda continua grave, a grande esperança está na Transposição do Rio São Francisco, obra que foi concluída e iniciou em 2017 a abastecer o açude.

$\mathrm{O}$ ano de 2011 foi bastante favorável à agricultura, caracterizando-se principalmente pela média pluviométrica de $1.494 \mathrm{~mm}$. As precipitações em 2012, 2013 e 2014 foram, respectivamente, $604,5,752,8$ e 705,5 mm. Isso reduziu a quantidade produzida e o rendimento médio de algumas culturas agrícolas permanentes.

Não houve redução de área plantada (disponível) e colhida das culturas durante 2011-2014. Isso aconteceu em função da elevada precipitação em 2011 e de valores próximos à média em 2012, 2013 e 2014 (Figs 3 A e B). Logo, evidencia-se que a seca não foi tão intensa para as culturas agrícolas permanentes. Até porque as culturas permanentes já estão "situadas", com raízes profundas, etc.

Houve redução da quantidade produzida (ton) de banana, coco, goiaba, laranja, mamão e manga durante 20112014. A maior redução aconteceu durante 2012 e 2013. Os valores das culturas mais expressivas foram os seguintes em 2011, 2012, 2013 e 2014: Banana: 320, 320, 220 e 375 ton; Coco: 180, 80, 60 e 80 ton; Mamão: 80, 40, 80 e 105 ton (Fig. $3 \mathrm{C}$ ). 


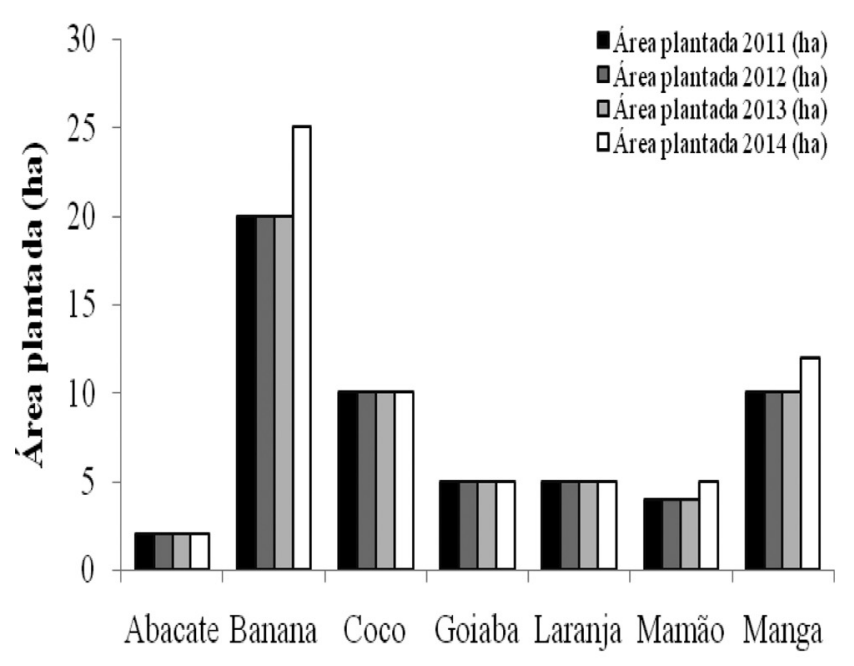

Culturas agrícolas

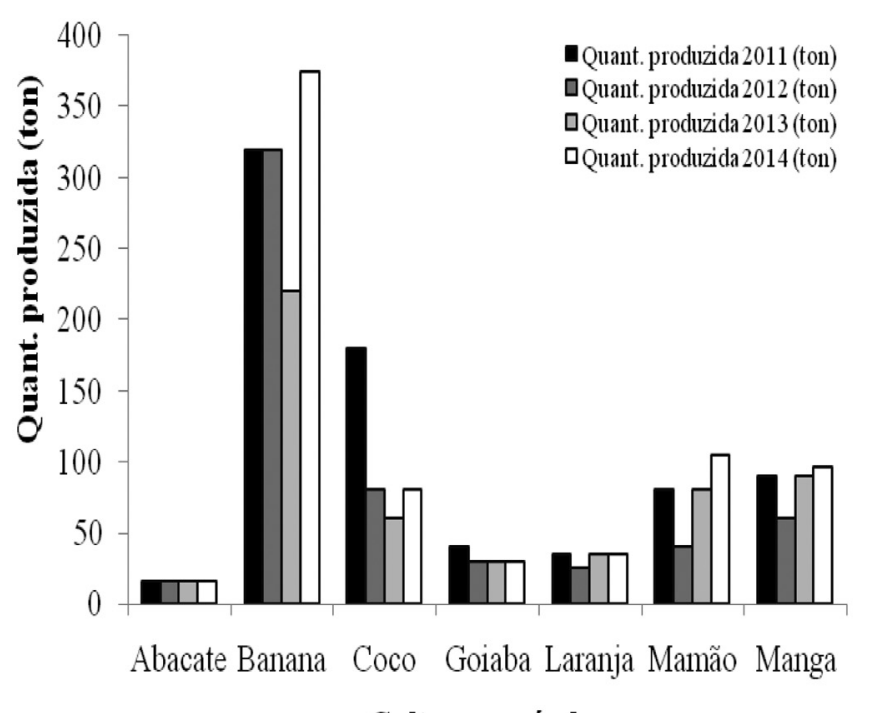

\section{Culturas agrícolas}

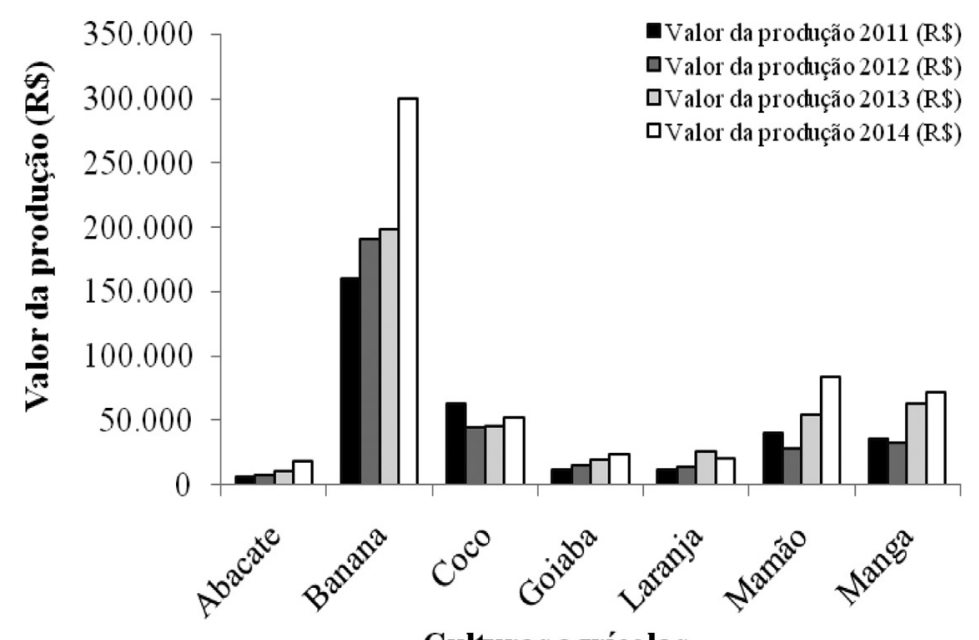

Culturas agrícolas

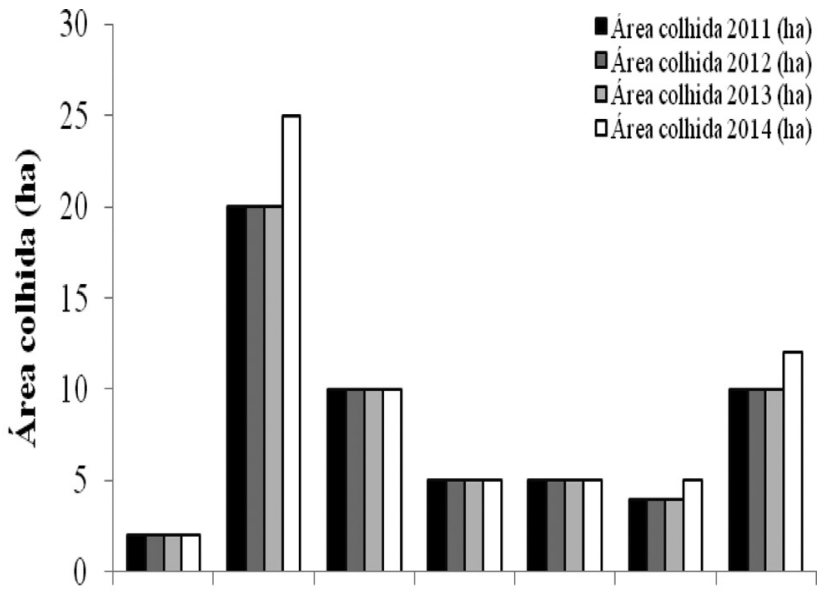

Abacate Banana Coco Goiaba Laranja Mamão Manga

Culturas agrícolas

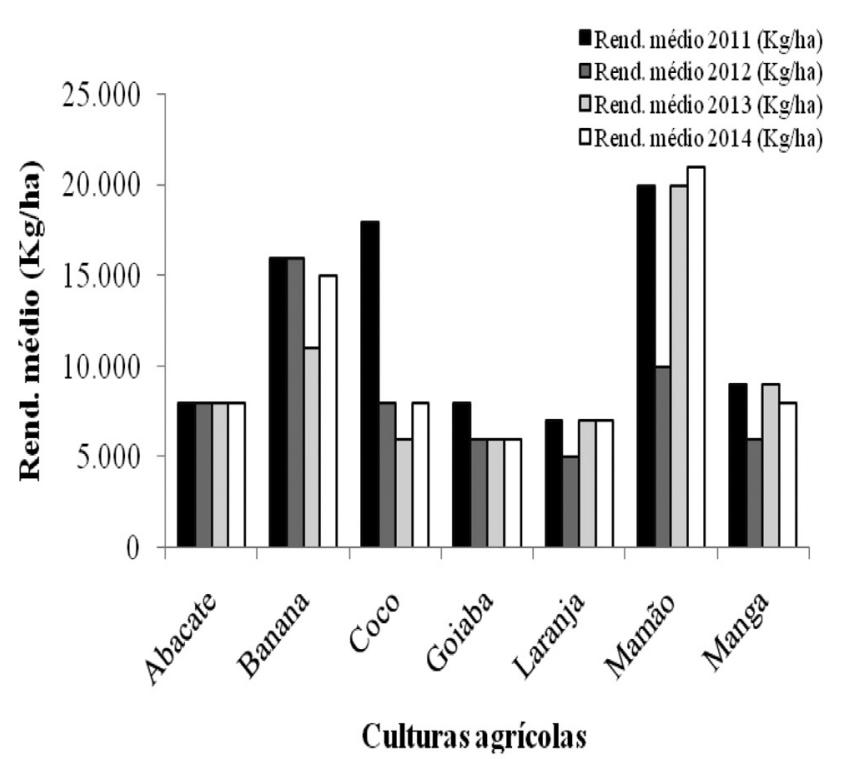

or da produção 2011 (R\$)

Figura 3 - Impactos da seca de 2012-2014 na área plantada (ha) (A), área colhida (ha) (B), quantidade produzida (ton) (C), rendimento médio (kg/ha) (D) e valor da produção (R\$) (E) das culturas agrícolas permanentes no município de Campina Grande-PB. Fonte: (IBGE, 2016). 
Também houve redução do rendimento médio por hectare das culturas em função da seca. $\mathrm{O}$ rendimento médio em 2011, 2012, 2013 e 2014 foi, respectivamente, banana, $16.000,16.000,11.000$ e $15.000 \mathrm{~kg} / \mathrm{ha}$; coco, $18.000,8.000,6.000$ e $8.000 \mathrm{~kg} / \mathrm{ha}$; e mamão, 20.000 , $10.000,20.000$ e $21.000 \mathrm{~kg} / \mathrm{h}$. As outras culturas tiveram menores reduções (Fig. 3 D).

Mesmo com a redução da quantidade produzida, a maioria das culturas apresentaram aumento no valor da produção, são elas: abacate, banana, goiaba e laranja, (Fig. 3 E), isso está ligado à lei da oferta e da procura.

A seca em 2012, 2013 e 2014 impactou negativamente as culturas agrícolas temporárias no município de Campina Grande. Na Fig. 4 é possível observar os dados referentes à área plantada (ha), área colhida (ha), quantidade produzida (ton), rendimento médio ( $\mathrm{kg} / \mathrm{ha})$ e valor da produção $(\mathrm{R} \$)$.

Com exceção da mandioca, todas as outras culturas tiveram redução de área plantada (ha) em 2012, 2013 e 2014. A maior ocorreu com as culturas de feijão e milho, isso causou impactos gravíssimos, pois são alimentos que garantem a subsistência da população. A área plantada com feijão e milho em 2011, 2012, 2013 e 2014 foi, respectivamente, $4.000,3.100,2.700$ e 2.900 ha; $2.800,2.600$, 2.400 e 2.500 ha, (Fig. 4 A).

A área colhida está diretamente relacionada com a plantada. A redução da área plantada em 2012, 2013 e 2014 resultou em menor área colhida. Algodão herbáceo, fava, mandioca e tomate tiveram toda a área que foi plantada, colhida. O oposto aconteceu com feijão e milho. Para estas culturas as áreas colhidas em 2011, 2012, 2013 e 2014 foram: feijão, $4.000,1.400,2.700$ e 2.900 ha; e milho, $2.800,1.000,2.400$ e 2.500 ha, respectivamente, (Fig. 4 B).

A quantidade produzida (ton) teve grande redução, principalmente no primeiro ano de seca (2012), havendo considerável aumento em 2013 e 2014. Isso ocorreu porque 2012 foi o ano com maior déficit hídrico, com o aumento das chuvas em 2013 e 2014 (valores próximos da média), houve aumento da quantidade produzida. Os valores foram os seguintes em 2011, 2012, 2013 e 2014: algodão herbáceo, 10, 2, 0 e 0 ton; fava, 129, 26, 190 e 49 ton; feijão, 720, $100,1.430$ e 580 ton; mandioca, $1.000,600,1.200$ e 1.300 ton; milho, 420, 50, 1.200 e 500 ton; e tomate, 800,200 , 1.200 e 880, respectivamente, (Fig. 4 C).

Houve redução do rendimento médio por hectare das culturas em função da seca. A maior redução ocorreu durante os anos de 2012 e 2014 (Fig. 4 D). Na Fig. 4 E é possível observar a redução do valor da produção entre 2011, 2012, 2013 e 2014. Mais uma vez, o pior resultado foi obtido para o ano de 2012, havendo um aumento em 2013 e 2014. Foi possível observar que os maiores impactos ocorreram para as culturas temporárias, muito em função da precipitação irregular temporal e espacialmente.

Ocorreu redução do efetivo de animais durante a seca, principalmente em 2012 e 2013. A menor redução ocorreu com os asininos, codornas, equinos, muares e suínos. Já a maior foi sentida pelos bovinos, caprinos e ovinos. A quantidade de bovinos, caprinos e ovinos criados em 2011, 2012, 2013 e 2014 foi de 20.931, 17.500, 18.000 e 17.000 animais; $2.500,2.100,1.928$ e 2.200 animais; e 3.700 , 2.800, 3.600 e 4.300 animais, respectivamente, (Fig. 5). Com a redução de água e alimento durante a seca, os rebanhos foram sendo reduzidos. A maior quantidade de bovinos em relação aos caprinos e ovinos é devido o município ser uma bacia leiteira de grande importância, com várias associações e cooperativas de beneficiamento do leite de vaca. Destaca-se também a pecuária de corte.

O déficit hídrico em 2012 dificultou o desenvolvimento das pastagens, influenciou fortemente o efetivo do rebanho bovino, causando redução na produção do leite. Com a diminuição de bovinos em 2012, a quantidade de leite produzido reduziu, passando de 3.780 .000 litros em 2011 para 3.000.000 em 2012. Mesmo com a seca em 2013 e 2014, houve aumento da quantidade de leite produzido em relação ao ano de 2011, isso ocorreu em função da utilização de silagem, feno, farelo de trigo, milho e algodão para alimentar os animais (Fig. 6 A).

Não houve relação entre redução da precipitação e da quantidade de ovos produzidos. A produção de ovos em 2011 foi de 697.000 dúzias, 792.000 em 2012, $800.000 \mathrm{em}$ 2013 e 850.000 em 2014 (Fig. 6 B). Isso justifica-se devido a precipitação em 2011 ter sido muito alta, proporcionando o armazenamento de grãos. Da mesma forma, a precipitação próxima à média em 2012, 2013 e 2014 permitiu que se desenvolvesse uma vegetação que favorece a alimentação de pequenos animais, principalmente aves.

O valor da produção de leite e ovos foi proporcional à quantidade produzida dos dois produtos. Só houve redução do valor da produção do leite em 2012, ano de seca mais intensa. Em 2011 o valor da produção do leite foi de $\mathrm{R} \$ 3.213 .000,2.850 .000$ em 2012, 4.400 .000 em 2013 e 4.680 .000 em 2014. Já os ovos foram vendidos pelos se-

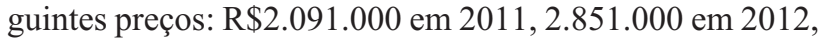
2.880.000 em 2013 e 2.890 .000 em 2014 (Figs 7 A e B).

\section{Conclusões}

As secas mais graves no município, aquelas com as maiores durações, déficits hídricos e intensidades, ocorreram nos períodos de 1997-1999, 2012-2015 e 2001-2003.

As culturas permanentes tiveram maior impacto na quantidade produzida e rendimento médio. Já as temporárias tiveram redução de área plantada, área colhida, quantidade produzida, rendimento médio e valor da produção. Os maiores impactos ocorreram para banana, coco, mamão, feijão e milho durante 2012 e 2013. Ocorreu redução do efetivo de animais durante a seca, principalmente em 2012 e 2013. A maior redução foi apresentada pelos rebanhos bovino, caprino e ovino. Com relação aos produtos agropecuários, só houve redução da quantidade e do valor da produção de leite durante 2012 e 2014. 

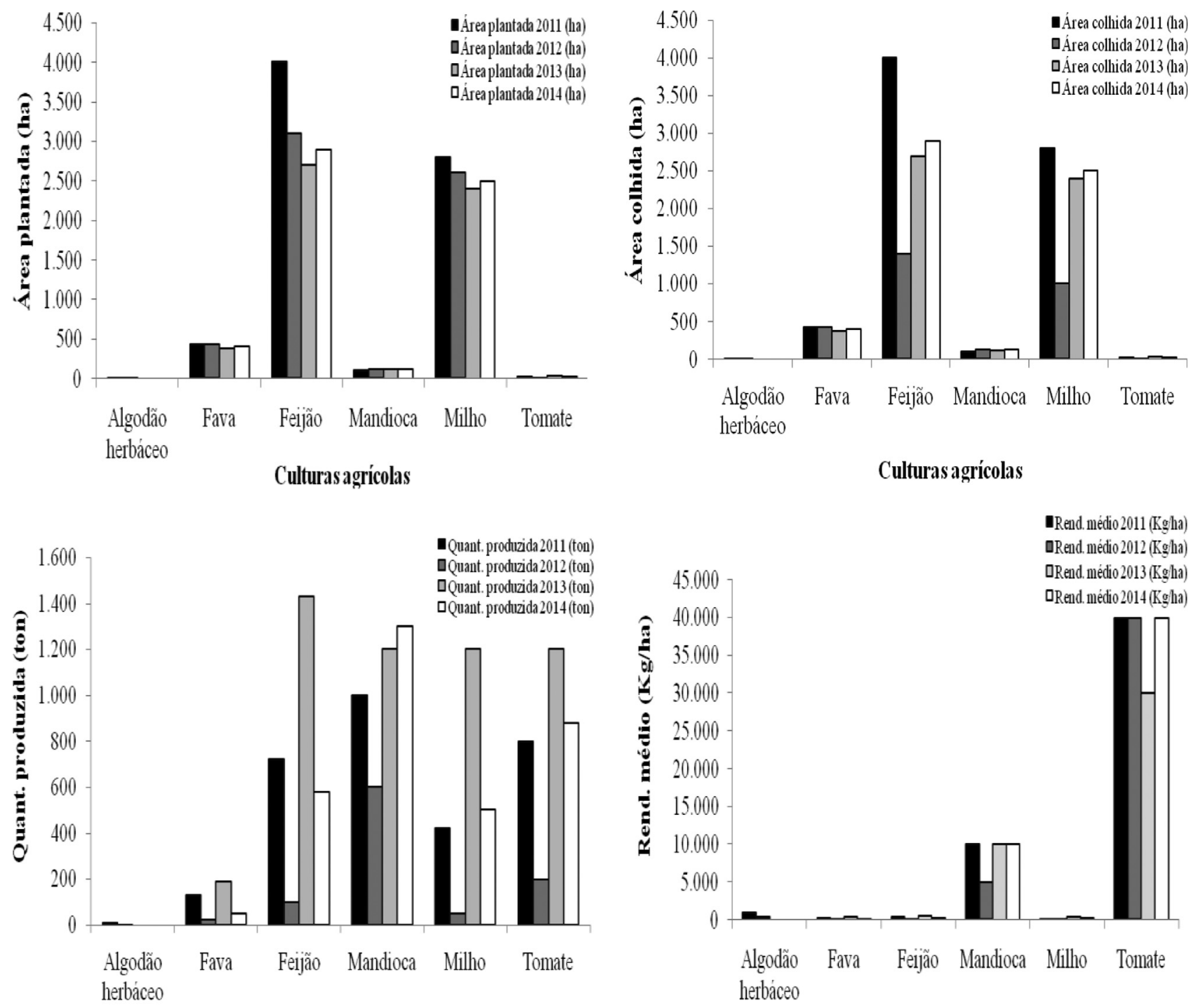

Culturas agrícolas
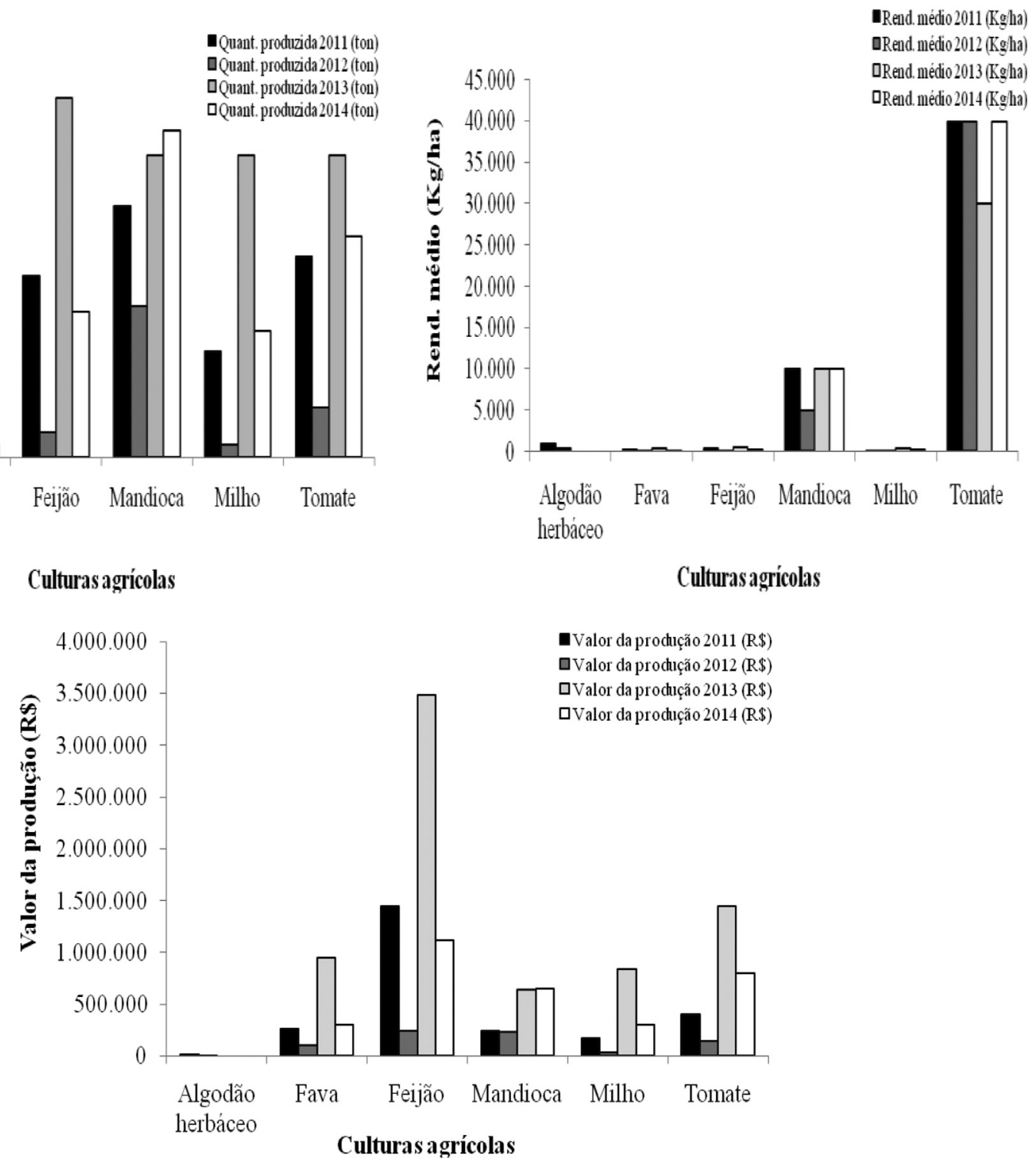

Figura 4 - Impactos da seca de 2012-2014 na área plantada (ha) (A), área colhida (ha) (B), quantidade produzida (ton) (C), rendimento médio (kg/ha) (D) e valor da produção (R\$) (E) das culturas agrícolas temporárias no município de Campina Grande-PB. Fonte: (IBGE, 2016). 


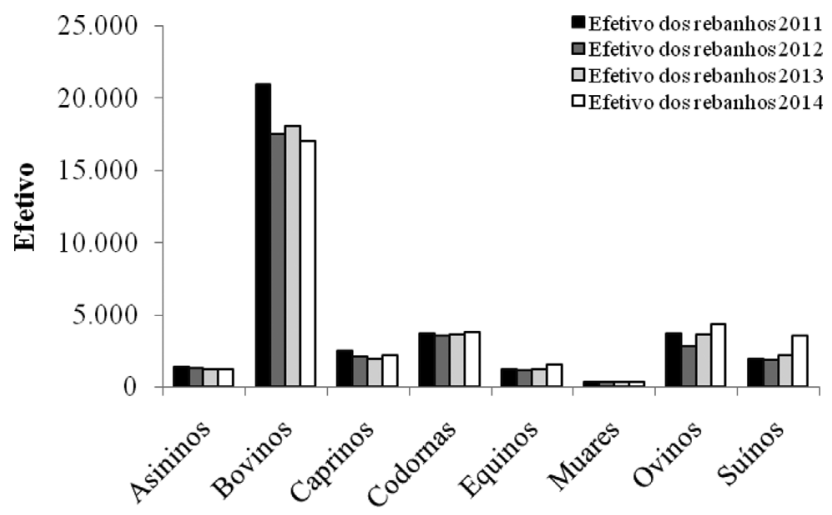

Rebanhos

Figura 5 - Impactos da seca de 2012-2014 no efetivo dos rebanhos no município de Campina Grande-PB. Fonte: (IBGE, 2016).
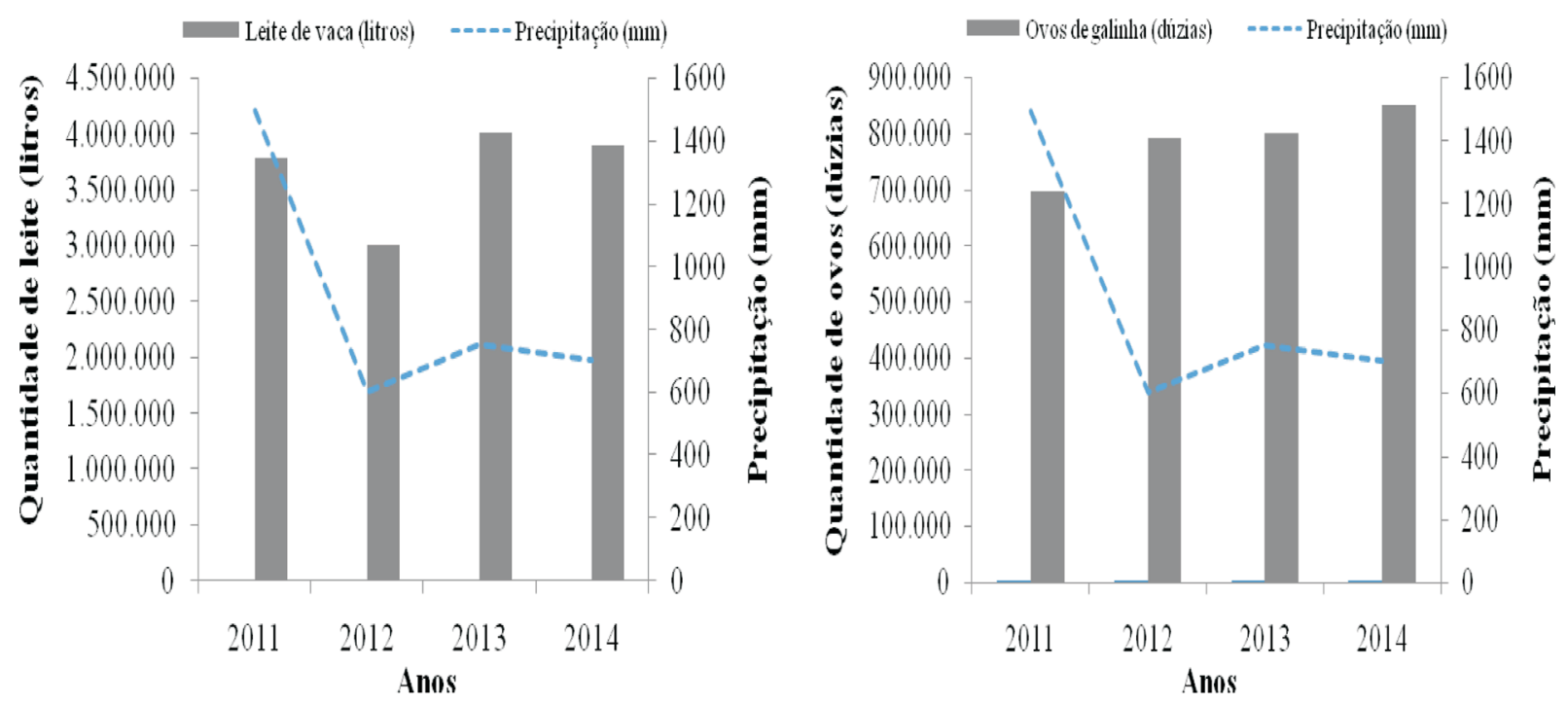

Figura 6 - Impactos da seca de 2012-2014 na quantidade de leite (A) e de ovos (B) no município de Campina Grande-PB. Fonte: (IBGE, 2016).
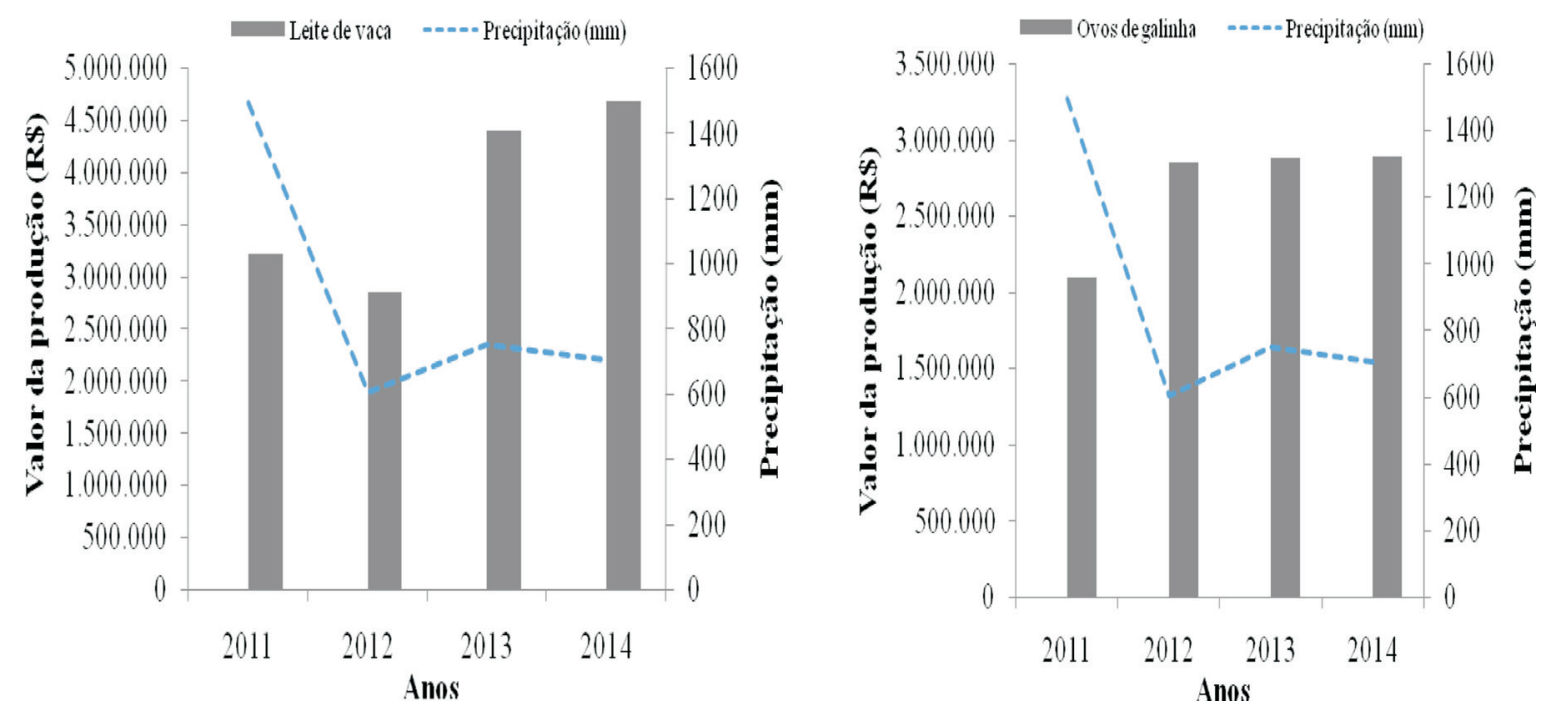

Figura 7 - Impactos da seca de 2012-2014 no valor da produção do leite de vaca (A) e de ovos de galinha (B) no município de Campina Grande-PB. Fonte: (IBGE, 2016). 


\section{Referências}

AGÊNCIA EXECUTIVA DE GESTÃO DAS ÁGUAS DO ESTADO DA PARAÍBA (AESA). Precipitações. Disponível em: http://www.aesa.pb.gov.br/trabalhosTecnicos/trabalhos/. Acesso em: 15/10/16.

BRASIL. SUDENE. Manual das comissões municipais. Recife: 1998.

BRASIL. As secas do Nordeste: uma abordagem histórica de causas e efeitos. Recife: SUDENE, 1981.

CANCELLIERE, A.; ANCARANI, A.; ROSSI, G. Distribuzioni di probabilità delle caratteristiche di siccità. Catania, 9-12 settembre, CUECM, Catania, p. 327-340, 1998.

CLAUSEN, B.; PEARSON, C.P. Regional frequency analysis of annual maximum streamflow drought. Journal of Hydrology, v. 173, p. 111-130, 1995.

FARIAS, A.A.; SOUSA, F.A.S.; MORAES NETO, J.M.; ALVES, A.S. Secas e seus impactos no município de Boqueirão, PB, Brasil. Revista Ambiente \& Água, v. 12, n. 2, 2017.

FARIAS, A.A. Caracterização e análise das secas na sub-bacia hidrográfica do Rio Taperoá e avaliação dos impactos e ações de convivência com a seca de 2012-2014 no município de Taperoá - PB. 2016. 185f. Tese (Doutorado em Recursos Naturais) - Universidade Federal de Campina Grande, Campina Grande-PB, 2016.

HAYES, M.J.; SVOBODA, M.D.; WILHITE, D.A.; VANYARKHO, O.V. Monitoring the 1996 drought using the Stan- dardized Precipitation Index. Bulletin of the American Meteorological Society. v. 80, n. 3, p. 429-438, 1999.

INSTITUTO BRASILEIRO DE GEOGRAFIA E ESTATÍSTICA. (IBGE). Produção agrícola e pecuária municipal. Disponível em: http://www.cidades.ibge.gov.br/xtras/perfil.php?lang=\&co dmun $=251650 \&$ search $=$ paraiba campinagrande. Acesso em: $15 / 10 / 16$.

KHAN, A.S.; CAMPOS, R.T. Efeito das secas no setor agrícola do Nordeste (Estudo Especial), Universidade Federal do Ceará, Fortaleza, 1992.

MACEDO, M.J.H.; GUEDES, R.V.S.; SOUSA, F.A.S. Monitoramento e intensidade das secas e chuvas na cidade de Campina Grande/PB. Revista Brasileira de Climatologia, v. 8, p. 105-117, 2011.

NANDINTSETSEG, B.; SHINODA, M. Assessment of drought frequency, duration, and severity and its impact on pasture production in Mongólia. Natural Hazards, v. 66, p. 9951008, 2013.

PROJETO ÁRIDAS. Nordeste: uma estratégia de desenvolvimento sustentável. Brasília: Ministério do Planejamento e Orçamento, 1998.

WILHITE, D.A.; GLANTZ, M.H. Understanding the drought phenomenon: the role of definitions. Water International, v. 10, p. 111-120. 1985.

YEVJEVICH, V. An objective approach to definitions and investigations of continental hydrologic drought. Hydrology paper. n. 23. Colorado State University, Colorado. 1967.

This is an Open Access article distributed under the terms of the Creative Commons Attribution Non-Commercial License which permits unrestricted non-commercial use, distribution, and reproduction in any medium provided the original work is properly cited. 